\title{
Linguistic Implications of Political Tweets
}

\author{
Abdulaziz Alshahrani ${ }^{1}$ \\ ${ }^{1}$ Department of Foreign Languages, College of Arts and Humanities, Albaha University, Saudi Arabia \\ Correspondence: Abdulaziz Alshahrani, Department of Foreign Languages, College of Arts and Humanities, \\ Albaha University, Saudi Arabia. E-mail: A.shahrani@bu.edu.sa
}

Received: May 11, 2020

doi:10.5539/ijel.v10n4p203
Accepted: June 9, 2020 Online Published: June 23, 2020

URL: https://doi.org/10.5539/ijel.v10n4p203

\begin{abstract}
Among the social media, Twitter is widely used by political leaders and the public to express opinions about various political issues. These tweets may influence the course of major political events like elections, Brexit and popularity of certain politicians. This common observation led to the research question of this paper: What are the political implications of Twitter postings? To answer this research question, an exploratory qualitative review of tweets was undertaken. Google Scholar was searched using the topic itself as the search term twice with two different time frames till 2019. The search yielded 41 papers. The papers were listed with brief description. A table categorising the methods used in the papers was useful to derive some conclusions. Generally, Twitter can be used for both positive and negative purposes and it can impact either or both the leader and the people who read them. Certain factors are involved in determining the nature of post and its outcomes. Many theories and methods had been used in the papers. Manual, machine learning and automatic analytical tools have been tested and used widely. None of the methods is perfectly suitable for all types of Twitter analysis. General content textual descriptions, characteristics of the texts, symbols, hidden meanings and presentation methods have been used in the tweets examined by the authors. The potential of negative tweets and hate speeches is quite clear. Absence of internal standard definition of these types of posts stands in the way of effective prevention. Some recommendations have been listed based on the findings of this review. A few limitations of this review have also been listed.
\end{abstract}

Keywords: Twitter, Trump's tweets, political leaders' tweets, elections, tweet deletions, extremist tweets

\section{Introduction}

There are many social media websites like Facebook, WhatsApp, Twitter, Instagram, LinkedIn and many more. They have become the easiest and instant communication tools for the general public. It is possible to share text messages, links, videos, audios and other multimedia materials through these social sites. Seeing their largescale impact, millions of people all over the world use these social media for various purposes. Of the different types of social media, Twitter has been becoming popular very rapidly. We look at some properties of Twitter which contributes to its increasing popularity.

\section{Distinguishing Features of Twitter}

Twitter is a social networking microblogging service which allows users to broadcast their posts. Thus, all posts in Twitter are publicly visible. Hashtags can be used to reach out to certain interest groups of choice. Word limit, spamming, limitations on number of followers to 2000 and its addictive nature are some disadvantages. A Retweet is a re-posting facility of a tweet. Retweet feature helps quickly sharing of own or another person's tweet with all the followers. Another facility is subtweet (subliminal tweet) a tweet about someone without mentioning the real or username of the person.

The above characteristics of Twitter make it an ideal medium for all types of tweets related to political topics. Twitter is widely used by political parties, political leaders and the public to express opinions about various political issues. Sometimes, Twitter can determine or change the course of election results in a country. These observations lead to the following research question for this paper: What are the political implications of Twitter postings?

To answer this research question, we explore some selected literature from Google Scholar on the linguistic implications of political tweets. 


\section{Methodology}

The first five pages of Google Scholar was searched using the above review topic itself as the search term with the only restriction that the language is English. All papers relevant to the topic published until 2019 were selected. The search yielded 40 papers. A PRISMA flow diagram is given below.
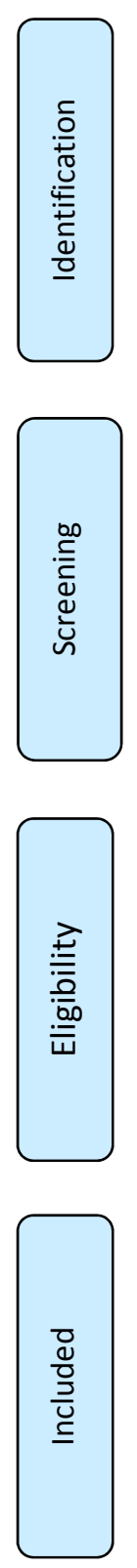

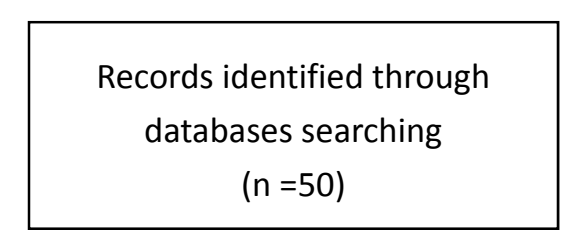

$(\mathrm{n}=50)$
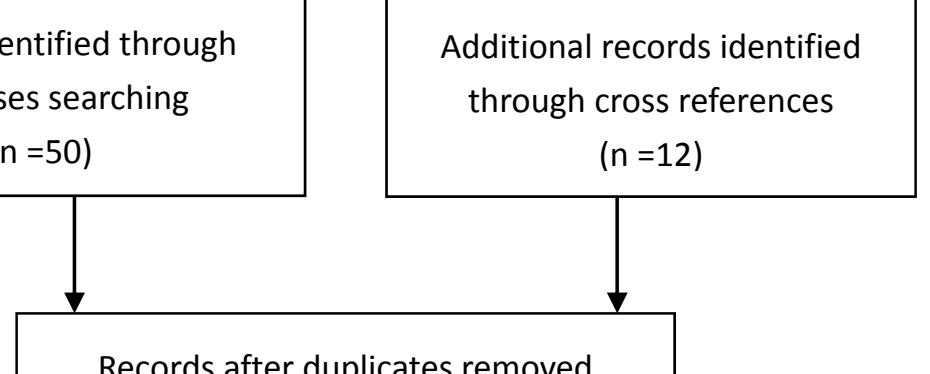

Records after duplicates removed
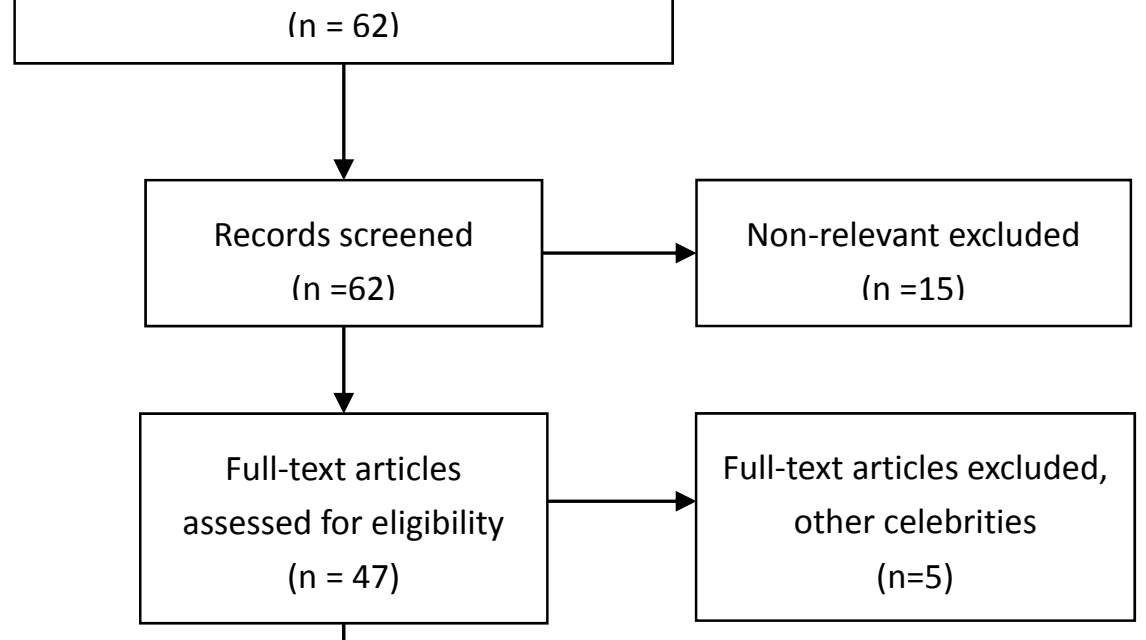

Studies included in

qualitative synthesis

$$
(n=42)
$$

Studies included in

quantitative synthesis

(meta-analysis)

$$
\text { ( } n=42)
$$

Figure 1. PRISMA flow diagram

\section{Results and Discussion}

The results of reviewing the selected papers are described along with the discussion as the explanations given by the authors of papers cannot be separated into a separate discussion section, as will be evident from the descriptions below.

The papers were categorised based on the research methods used in the papers as shown in Table 1. 
Table 1. Number of papers related to each method of Twitter analysis

\begin{tabular}{lll}
\hline Research method & No of papers & \\
\hline Linguistic analysis & 12 & Includes one paper cited twice. \\
Content analysis & 23 & Includes ref for CDA and one paper cited thrice. \\
Models & 15 & \\
\hline
\end{tabular}

Content analysis accounted for about half of the total papers. Linguistic analysis and proposal of models were almost equal. These are discussed in the following sections.

\subsection{Linguistic Analysis}

The selected papers demonstrated both linguistic and content analysis of political tweets related to different parts of the world. Ott (2017) commented about the wholly homologous nature of Twitter itself and the natural speaking style of Trump's tweets on 12 November 2012 and responses to it and the tweets on 5 April 2016, 27 April 2016 and 5 May 2016. A Twitterbot developed by Brad Hayes of MIT in which he had programmed a Twitterbot to mimic the then presidential candidate. The bot used an artificial intelligence algorithm based on Trump's language in hundreds of hours of debate transcripts to generate Trump-like tweets. Trump's debate rhetoric during the Republican primary had three prominent features. The language was simple, deferred to trusted friends and colleagues and consistently insulted his opponents. The first and third of these features are common for many other tweets by different people. The bot was able to generate some real tweets of Trump due to these similarities. The language of Trump's ordinary speech had been darker, more violent and contained strong words of insults. He used block capitals for exclamatory points.

A linguistic approach was used by Nasser and Kareem (2018) to analyse the tweets of Trump. The authors used "the propositional content condition and essential condition model of Searle (two aspects of meaning that are expressive of the factuality of what is said or written), Grice's cooperative principle and relevance (meaning that the speaker is delivering a verbal turn that is relevant or related to the topic discussed) and Mahootian's code-mixed discourse. Mahootian applied a discourse-based analysis to decode online blogs and texts with an emphasis on lexical change, speakers' intentions, and interaction maximization." (p. 4). These analyses showed that Trump used very informal rhetoric when criticising, slashing, sharp judging and directly attacking. The tweets are brief, purposeful, and objective with a definite aim. There is a mixture of praise, dispraise, thanking, briefing, lamenting and discomfort his tweets. To emphasize points, he uses block letters and exclamation marks. Preoccupation with modern life and anxiety about self can cause such methods of expressions. In linguistic terms, he gives importance to certain grammatical devices and structures like interjections, adjectival phrases and comparative degrees, and lengthy sentences. There is also an overuse of future tense (will) especially in dealing with issues, promises, calls or threats.

Measures of public opinion derived from polls could be correlated with the sentiment word frequencies in Twitter messages, which was associated with several time series surveys on political opinion of the public done several times during US elections of 2010 (Stieglitz \& Dang-Xuan, 2012).

Measures of public opinion derived from polls could be correlated with the sentiment word frequencies in Twitter messages, which was associated with several time series surveys on political opinion of the public done several times during US elections of 2010 (Stieglitz \& Dang-Xuan, 2012).

What was true in the case of Trump during US elections were also true in the case of Columbian elections. Casarin et al. (2019) used an inverse Bayesian method to analyse political tweets of this election. Politicians were able to identify the combination of sensitive words to enhance the probability of retweet of the message to impact on political outcomes. Trigram was used as the method of analysis of Spanish tweets. Retweets were able to predict election outcomes. Low grammatical density resulted in using more words to express the same ideas in Spanish compared to English. Thus, the information contained in an average bigram in English was similar in amount as a trigram in Spanish. Trigram analysis, especially in the context of retweeting and its impact on voting in Spanish was different from other works on English language tweets which can use bigrams. The combination of words 'paz' (peace), 'política' (politics) and 'mujeres' (women) were frequently used during the 2015 campaign by Colombian politicians. This had led to the immense political polarisation between the former Colombian president Alvaro Uribe Velez and the current president Juan Manuel Santos on the topic of peace talks with Revolutionary Armed Forces of Colombia (FARC) during both legislative and executive elections in Colombia in 2014. The significance of the word 'mujeres' arises from their important role in the Colombian peace through the participation of 'Corporación Sisma Mujer', one of the most well-known Colombian women's rights NGOs. Politicians used trigrams frequently in a stereotyped manner for 'personalised' contacts with their 
followers. For this purpose, they propagated messages with formal greetings using demonyms to draw the attention of people from specific areas. The tweets, 'buenos días santandereanos' and 'buenos días Cordoba' exemplified this. However, the sentiment reduction score of all political parties were similar.

Instead of simple word analysis or inverse Bayesian model with bigrams and trigrams, critical discourse analysis (CDA) (Wodak \& Meyer, 2009) in a socio-cognitive ideological frame can be used, as was demonstrated by Masroor, Khan, Aib and Ali (2019) while analysing the tweets of two prominent Pakistani political leaders. The variety of discourse strategies were noted, in which, cognitive binary of positive self-presentation and negative other-presentation to achieve political domination and legitimization of political actions by controlling the public opinion were expressed. The contexts of motives ranged from restoring public faith in the governance to toppling the government.

Gender may play an important role in determining the language used in distinct ways. The differences are related to their expected roles in the social groups. This is a linguistic phenomenon happening in several cultures and relates to their discursive strategies. In political tweets during the 2010 Brazilian presidential campaign analysed by Cunha, Magno, Gonçalves, Cambraia and Almeida (2014), men used imperative verbal forms in hashtags more frequently in expressing their attitude towards a particular candidate. Women used more of declarative forms. This difference was attributable to their distinct approaches towards others in the network. When political hashtags are used as strategies of persuasion, imperative forms become more overt ways of persuading and declarative forms more indirect ways of persuasion. The relative effectiveness of the two forms were certainly different. No negative sentiment against any candidate was expressed by any of them in the tweets.

Talking of sentiment, the sentiment word frequencies in tweets could be correlated with several time series surveys on political opinion of the public. Stieglitz and Dang-Xuan (2012) examined the political tweets, published on Twitter from March 21 to 27, 2011, just before the two Landtag (state parliament) elections in Baden-Württemberg and Rheinl and Pfalz states of Germany. The tweets of parties and frontrunners in the elections were examined. Interactive and intensive discussions related to these elections were identified. A few users published most of the tweets. Their influential role was evident from the numerical strength of retweets. The relationship of sentiment in political messages with certain political parties or politicians and their retweetability was measured. Tweets containing affective expressions were retweeted more than those which did not contain such words. Thus, messages containing affective expressions can be used for their rapid spread. Leftists functioning as actors accounted for maximum retweets reflecting in the election results. This finding highlighted on the need for politicians and political parties to identify the most influential users and follow the discussions with strong affective sentiment among their peers, especially during election campaigns. Political parties and politicians should Use of social media intelligence similar to business contexts is recommended for political parties and politicians.

Lexical and social network alignment can reveal political alignment of twitter users. The discourse patterns in tweets, retweets and replies can reveal political affiliation of the users. Rates of using capitalization and punctuation can also indicate this. Smaller proportion of replies with more punctuation and capitalisation were noted in the case of right-winged users. Although there were robust differences between left and right leaning groups with respect to their discourse and sub-lexical features, their predictive accuracy was low (Tatman, Stewart, Paullada, \& Spiro, 2017). In a study on the linguistic features present in populist discourse on tweets by four European political leaders-Luigi Di Maio, Matteo Salvini, Marine Le Pen and Nigel Farage and its relationship with their popularity, Carrella (2018) identified emotionalization, simplistic rhetoric and intensified evaluations as the discursive elements of populistic expressions. A control group of Matteo Renzi, François Hollande and David Cameron was used for comparison in the analysis. These discursive features were positively correlated with the tweet popularity for both the leaders in question and the control group. Leaders of the control group tweeted stronger presence of populist-related features.

Use of personal pronouns in Twitter were examined by Jaworska and Sogomonian (n.d.) to find out their effects in the EU Referendum of 23 June 2016 in UK in relation to Brexit. There were significant differences in the use of personal pronouns by Leavers and Remainers. Use patterns of "we" was significant distinguishing factor in the rhetoric of both groups. Leavers used "we" more frequently and in more versatile manner to mobilise diverse types of supports. The use of "we" was particularly noticeable when the disadvantages of continuing in EU were discussed. This was especially observable when the disadvantages of continuing in EU were contrasted with alternatives. The disadvantages included payment of $£ 350 \mathrm{~m}$ per week for EU public services, threat to safety, security and quality of life due to free migration within EU, political future of the country, EU constraints on the open citizenship in a thriving democracy and global trade. The Brexit economic advantages for families, farmers and consumers on the priorities of the country rather than that set by EU were contrasted. "If we leave" 
advantages were more than "if we stay" disadvantages. On the other hand, projection of economic losses, higher prices and job cuts by leaving Brexit were prominent on the other side. The influential Leave tweets projected the current state as negative, blamed the EU for it and then suggested Brexit was the solution to these problems and a bright new future for UK. On the other hand, the influential Remain tweets projected Brexit as something bad or to be afraid of and benefits of being within EU were rarely stressed. This caused the Leavers naming Remainers as "Project Fear" in some tweets. Tory Brexit and Labour No Brexit projected the distinct political polarisation also. However, some prominent leaders of Labour party supported Brexit and therefore, the Remain tweets were not effective.

\subsection{Content Analysis}

Instead of linguistic analysis, the contents of tweets were analysed as such in some papers. In the 2010 US Congressional elections, the tweets and retweets contained posts of divisive partisan structure. Retweets were used as a mechanism of spreading information (Stieglitz \& Dang-Xuan, 2012). Tweets of former US President Barak Obama, former British PM David Cameron and Israel PM Benjamin Netanyahu were aimed at improving outreach and transparency (Aharony, 2012). The political discussions in Twitter during political elections were aimed at the most active and most influential users either to protest or express positive or negative sentiments (Stieglitz \& Dang-Xuan, 2012). Colleoni, Rozza, and Arvidsson (2014) divided the users into Democrats and Republicans on the basis of tweets. Political homophily of both unreciprocated and reciprocated tweets were examined for the two groups. Higher levels of political homophily were observed in the case of Democrats. On the other hand, stronger homophily were noticed in the case of those Republicans who followed official Republican accounts and it was higher than those of Republicans themselves. Reciprocated tweets showed higher political homophily than unreciprocated ones. The linguistic features of the postings were distinct in all these differentiations which facilitated identification of these trends.

In their work, Pancer and Poole (2016) analysed the first three months of tweets from Hillary Clinton and Donald Trump after winning their respective nominations. They observed that messages containing \#hashtags, @ usermentions, or http://www.websitelinks.com decreased likes and retweets. These features are meant to increase audience exposure. However, their presence simultaneously increased disfluency or the subjective difficulty of cognition. Thus, the message become less visually clear leading to perceptual disfluency. Then they required the translation of symbols and text strings into meanings in terms of orthographic disfluency. Features like embedded images improved processing fluency leading to increased interactions. Thus, fluency in brief WOM transmissions becomes important. This stresses the need to device suitable social media strategies to influence the voting public.

In their study, Ramanathan, Bee and Paramasivam (2017) used Fairclough's three dimensional model to analyse the lexical choices and the formation of ideas to compare the ideological notions in the political tweets of Prime Minister Najib Tun Razak (henceforth, Najib) in Malaysia and Prime Minister Narendra Modi (henceforth, Modi) in India during the election campaigns. Data were collected over a period of 3 months during the election campaigns which occurred from February to April 2013 in Malaysia and January to March 2014 in India. The presence of various ideologies in the tweets demonstrated the consensual power of the political leaders. This was reflected in the citizens' acceptance of their principles, ideologies and moral values. Political awareness among citizens and the language used by both leaders from different political coalition were important. Usefulness of Twitter for success in elections was also evident.

Twitter doubled the permissible word limit in November 2017. Jaidka, Zhou and Lelkes (2019) used both supervised and unsupervised natural language processing methods to analyse 358,242 tweet replies to U.S. politicians from January 2017 to March 2018. The effect of doubling the permissible word limit resulted in less uncivil, more polite, and more constructive discussions online. However, the trend of declining empathy and respectfulness of these tweets remains major concerns.

The language used by Belgian and Spanish politicians in their tweets during the 2014 European elections were studied by Coesemans and De Cock (2017). It was noted that politicians adapted to technological limitations of Twitter using concise statements with subject pronoun ellipsis in Dutch and full subject NP constructions of a first-person plural verb form in Spanish and Catalan to accommodate their tweets within the 140-word limit. Exact conciseness strategies are determined by features related to the language. Twitter handles and hashtags were used for promotion of personal branding. Metapragmatic awareness was indicated by first person pronouns and proper nouns for creative and third person references. Twitter was used for making their campaign talk searchable and possible to be followed.

Politicians tweet to promote the "us vs. them" split in the population during social uprisings. They aim to obtain 
support and legitimization for their own actions. Using critical discourse analysis (Wodak \& Meyer, 2009), Karkın, Yavuz, Parlak and İkiz (2015) examined the repeating frequencies of speech patterns in the tweets of leading politicians during the Gezi Park protests, which originated in Istanbul Turkey in June 2013 and spread across the country rapidly. The discourses in the politicians' tweets deliberately tried to guide the public to reproduce marginalization and polarization among them.

The processes of creating and sharing social media posts during live political debates were investigated by Berman, Melumad, Humphrey, and Meyer (2019) analysed the live political debates over four key issues from over 9.5 million tweets just before the 2016 US presidential election. As the debates progressed, the tweets were increasingly decoupled from the live event. The success drivers of tweets were different during the debates and after the debates. During the debates, users acted like narrators. They posted shorter tweets commenting on the events which were developing. Linguistic emotionality had a limited role in sharing. After the debates, users assumed the role of interpreters. Successful posts were more detailed containing visual and emotional accounts of the events. Barack Obama's last State of the Union Address was analysed for generalisation of the findings.

Trump's supporters stayed with him on his environment policies all the time as reflected by their tweets (Khan \& Khan, 2018). They used a variety of means for this purpose. They expressed resentment against the liberals. They approved all his actions. They were sceptic against the argument of climate change or environmental dangers. A strong sense of nationalism overshadowed the concern for economic wellbeing. The most dominating Their hostile attitude towards their political opponents dominated the entire discourse. They were not concerned about the economic benefit due to the pro-environment policies. Although some themes dominated more frequently, there was no variation in the expression of enthusiasm in respect of each theme. For a politician with an environment friendly outlook, voters were not feeling more strongly about certain themes regarding environmental policies. Rather, they were conditioned and were accustomed to think about certain themes more often.

Using a corpus analysis of Trump's discourse in his tweets both before and after becoming president, Ross and Rivers (2018) noted that Trump makes repeated attempts to ridicule the mainstream media using disparaging labels like "fake news" and "fake media." He seems to be attempting to deter the public from trusting media reports, since many of them criticise Trump's presidency. He wants to position himself as the sole source of truth. But objective truth can be contested. Hence, arguing the other way, Trump himself may be a serial offender in spreading mis- and disinformation in the same way as he accuses the media.

Based on a study of 577,555 tweets by over 400 members of the U.S. Congress between 2012 and 2014, Jones, et al. (2018) noted that Republican and conservative legislators highlighted on the values of tradition, conformity, national security and self - direction. The Democratic and liberal legislators, on the other hand, stressed on the values of benevolence, universalism, hedonism, social and economic security and achievement.

Political candidates occasionally slip up in election-related tweets and want to repair the miss. Such uncomfortable tweets are deleted hoping that none will notice. But Politwoops archives deletions of politicians to bring more transparency and accountability to political discourses. Discussing this issue, Meeks (2018) observed that analysis of Twitter deletions can reveal the campaigns that were strategically present which the candidates wished to hide from voters to create favourable attitude among voters leading to their winning the election.

Due to the growing amount of offensive communication on the internet, there is a growing need for a new technology to detect hate speech automatically for effective content moderation. However, defining exactly the difference between free speech and illegal speech depends on the laws in a specific country and knowing the linguistic characteristics of hate speech. Jaki and De Smedt (2019) analysed over 50,000 right-wing German hate tweets posted between August 2017 and April 2018 around the 2017 German federal elections. Both quantitative and qualitative methods were used. Subversive profiles containing various types of hate speeches, derogatory keywords and retweets were compared with safe tweets to evolve stylistic clues to identify hate speech. These speeches were targeted on persons, groups communities, races, activities and behaviours. Some lexical analysis identifying word bias or vocabulary of hate speech, word combinations to convey derogatory messages on religion, ideology, gender and race, dehumanisation naming persons as some animal, word clusters on immigration, refugees, politics, crime, word polarity, word tree were used. The identified linguistic creativities were: creative targeting using suitable word compounds, creative metaphors and phraseological modifications using film titles, proverbs etc. Speech acts which were expressive, directive, assertive, commissive, indirect were also identified. These manual methods of identification of hate speech linguistics were used for automation of the detection process for in-domain and cross-domain evaluations. 
Compared to politicians, terrorist groups handle Twitter in a negative way. Torregrosa, Thorburn, Lara-Cabrera, Camacho, and Trujillo (2019) compared the tweets from a dataset of 105 pro-ISIS users with 91 random Twitter users during 2015-2016 to find such negativism in text, tone and meaning. The Linguistic Inquiry Word Count (LIWC) software was used for this analysis. ISIS supporters used more third person plural pronouns and less first person singular and second person pronouns. They also used more words associated with death, certainty, anger and more words containing six letters or more. Their language use was similar to those of other extremist organisations.

Using experimental approach comparing proven disinformation (deceptive information) with new tweets, Volkova and Jang (2018) examined lexical markers of biased language, syntactic and stylistic signals and connotations in different types of deceptive news such as disinformation, propaganda and hoaxes. Some of the deceptive strategies including misleading or falsification were also evaluated. The tweet content along with biased language markers, moral foundations and connotations predicted the outcomes of deception strategies better than was possible with syntactic and stylistic signals. It was easier to identify falsification than misleading strategy. Prediction of disinformation was more difficult than of propaganda or hoaxes. Deceptive news types (disinformation, propaganda, and hoaxes), unlike deceptive strategies (falsification and misleading) were more prominent and hence easier to identify in tweets than in news reports. The analytical approach used in this paper enabled deeper understanding of the perspectives and thus revealed the intentions of such disinformation practices.

In Twitter, language styles are modified as well as influenced by the relationship of the person with others. However, the linguistic styles of people can be predicted by their demographic attributes like gender, age, place where they grew up and others. The linguistic style may also be changed according to the status of the persons or audience they address and the relationship of these persons with the user. Social acceptance also influences linguistic styles, like lower status people adapting the styles of higher status people. Each medium has its own style and so has Twitter. Designing of linguistic behaviour is largely based upon an imagined audience, although audience may consist of diverse types. According to Shapiro, Hemphill, and Otterbacher (2018) members of the U.S. Congress used Twitter for many of their speech-based actions. These tweets include brief account of how the day was spent, recent events, providing online or offline information and declaring position for or against policies and other politicians. But information provision with or without political positioning on various issues dominate all of them. Females, senators, and Democrats were more likely to tweet. The members of Congress had been routinely using Twitter with one-way communication as priority. They tweeted cleverly to provide for their framing efforts for positioning speech acts. However, there were no significant differences in advantages or disadvantages among these groups with respect to access or impact.

Some political crises happened in Brazil in recent years. Dilma Rousseff, the president, was impeached in 2016. Several corruption scandals were investigated in 2017. Teixeira et al. (2018) proposed a taxonomy for discourse analysis to understand the intent and types of tweets about political scandals. The number of retweets were almost half of all tweets, but the retweets had significant mass influence. Humour, criticism and protest were more prominent in these retweets. Whether joke or serious comment was determined by the nature of event and its likely influence on the Twitter users. Every crisis was not treated as a joke. Criticism and protests were more in the cases like bribery. Humour was more frequent in the case of a famous politicians, such as the ex-president Lula or president Temer. Taking sides to support a particular person was possible. In the case of some events, a surprise element was expressed in the tweets. Retweets were mainly determined by the sentiments and cultural factors. Images, videos and animated gif posts were intended as humour. Texts were used for criticisms and protests.

The Nigerian community has their own interesting and innovative methods of coining words for Twitter. During the time of the former President Goodluck Jonathan, his supporters were described using the words "Jonathanian" and "GEJites". The word "Buharist" became a similar word to support the then leading opposition candidate and now the President Mohammed Buhari. In this context, two words being used were "wailing wailers" and "hailing hailers". The former was meant to be a derogatory word against those whose tweets were critical of Buhari. The latter was used to describe the Buhari supporters. "Wailers" was an adaptation of another word, which was positive and radical in significance, as it was associated with Bob Marley in the seventies. Hence, although it was intended to be derogatory, critics of Buhari were happy to be labelled in that manner. On the other hand, "Hailers" was considered to be more damaging since it was phonically close with Hail Hitler banners and its associated image of unreflecting followership. Use of suffixes like "-ian", "-ite" and "-ist" were the preferred linguistic devices. Labelling in Nigerian Tweets were creative and at the same time part of the war of words and wits between persons at or near extremes of the political continuum. These were not ideological but emerged 
from the interaction of need, greed, creed and region of the political class. In this context, the new word, "Fencism" was not meant to be neutralism. Instead, "Fencism" objectivity. It considered the drawbacks of both sides and formed its own views. In "Fencism" an informed, detached and yet connected non-partisan and objectivity driven approach to behaviour was observable (Ihebuzor \& Egbunike, 2018).

According to the analysis of tweets by the Pope Francis by Genovese (2019) more political tweets were common during international crises. The target issues were related to other secular authorities. Sometimes, the tweets were also meant to normalise Catholic Church power to maintain the Vatican's long tradition of safeguarding peace and protecting vulnerable populations.

Microblogging posts of two major political parties and their political candidates in Nigeria extracted from the Twitter handles in the studies by Opeibi (2019). The tweets on the election-related issues trending during the period were collected as supplementary data. As a language accommodation strategy, the current opposition party in Nigeria, the People's Democratic Party (PDP), opened four Twitter accounts to accommodate the national multilingual setting. In 2015 elections, the current president Jonathan used Twitter for civic engagement and covertly solicit future support. Indirect communicative act is a characteristic of socio-cultural discourse based on presupposition. The passport size portrait picture of the candidate with a smiling face and relaxed mood was suggestive of a semiotic thrust. This positioning was used for communicating a message of optimism, friendliness and commitment to implement the electoral promise. Two slogans accompanied the tweets: Goodluck for Transformation; The Transformer was written in the lower section of the post to strengthen this message. All typical features of political tweets were fully evident in Jonathan's posts. His opponent used influential persons to support him expecting the common voters to follow the suit. The political parties and candidates used Twitter also for raising credibility of the election process of primaries in 2014. Monitoring and management of the electoral process in real time were posted in the All Progressive Congress (APC), the Buhari's party. Later these posts were improved with better displays. Retweeting was used by both parties for crowdsourcing for support. These retweets reiterated the campaign promises as the prime. Reconstruction, metaphorical and rebranding of their personality profile for crowdsourcing and followership were also aimed at. Ethical and hashtag persuasions and sloganeering, globalisation of local issues and use of saints and demons contrasts, rhetoric, acronyms, neologism, convention naming and mediating latest trending topics were used by both parties extensively.

The above section dealt with linguistic and word content analysis of tweets in various contexts. Some predictive models have been developed by a few authors based on the trends of tweets analysed in various ways. Some of these are discussed below.

\subsection{Models}

In both cases of Iranian and German elections of 2009, number of Twitter mentions could be correlated with election results. Relationship between the quantity of words indicating affective dimensions of both positive and negative emotions in the case of certain political parties or politicians with respect to rates of tweets and the retweets could be positive as per (Stieglitz \& Dang-Xuan, 2012).

A seven-point scale and a model were used by Preoţiuc-Pietro, Liu, Hopkins and Ungar (2017) to characterize the groups of politically engaged users through language use on Twitter. As against the commonly held view that ideology is a single, left-right dimension, in this research, it was found that self-reported political extremity is more an indication of political engagement than of ideological self-placement and only self-reported extremists devoted a lot of time for politics in their Twitter activities.

The relationship of sentiment (emotionality) with appraisals, frequencies and speed of dissemination were investigated by Dang-Xuan, Stieglitz, Wladarsch and Neuberger (2013). They analysed 30 most retweeted users for content-related features including emotionality, appraisal of political parties or politicians and topics in the case of state parliament election of Berlin.

Based on their research, Cohen and Ruths (2013) observed high level of inaccuracies in the ability of analysed content of tweets to predict political orientation. This was attributed to overoptimism arising from procedural errors in validation of data sets. The authors collected novel data carefully using annotation techniques. Three different types of Twitter users were collected. Each of these possessed a different degree of political engagement on Twitter. The users ranged from politicians who were highly vocal to those who were normal users, who did not discuss politics normally. Previous reports used standard methods of measuring political orientation to show $90 \%$ inference accuracy. They were found to have only $65 \%$ accuracy on normal users. This meant use of narrow range of political orientation for describing classifiers. 
Recognising the limitations of traditional linguistic approaches for sentiment analysis, Li, Chen, Ji, Muresan and Zheng (2012) used a combination of local linguistic features and global social evidence as an improved method of sentiment analysis. This method was tested in the case of US Presidential election. The main task was to classify political election tweets into positive and negative. The authors recognised tweets containing sentiments targeted specifically on candidates or parties and those which were forum posts containing both specific targets and issues like foreign policies. These were categorised as target dependent tweets and target-issue dependent forum posts. Positive instances for hashtags of Obama and GOP (Republican party candidates) were collected from the tweets. Discussion forum data were extracted from Elections and Campaigns board of political forum. Observations about current behaviour were used as causal explanations for past and future behaviours of the target. The analysis showed certain target-issue pairs to be consistently associated with a particular sentiment across most users. There were frequent positive sentiment about Ron Paul's foreign policy and negative sentiment about Barak Obama's foreign policy. These results were explained using impression formation theory. Mental grouping of familiar persons occurred through social categorisation process. Thus, to express sentiment on one target, an implicit comparison with another target was essential. Such comparisons may mix positive and negative sentiments like in, "NONE of the GOP candidates have a significant advantage on national polls against Obama." Here GOP and Obama are the two comparison targets. Positive sentiments are in "significant" and "advantage". Negative sentiments exist in "against" and "NONE". Sometimes consistent sentiments are expressed in certain target comparisons like in, "when compared to "McCain" or "Nixon", the sentiment towards "Barack Obama" is usually positive, while compared to "Washington", the sentiment is mostly negative". Using social balance theory, the interpersonal network among social agents were analysed to evaluate how a social group evolves to a possible balance state. Here, user was one agent and the two presidential candidates were the other two agents. Since the other two agents were competing, there was mutual negative sentiment between them. This means, the balanced state was attained when there were two mutual negative and one mutual positive sentiment. According to Halo Effect or Halo Error theory, a cognitive bias causes formation of a general impression of someone and any further information is assumed to support the first impression. Further, cognitive consistency occurs when people try to maintain consistency among their beliefs. Therefore, a user has a consistent sentiment not just based on a single first impression from the first inputs, but information added further to form a consistent belief. The most confident sentiment and most frequent sentiment with and without adjustment for confidence values were used here as tools of the two theories. When the sentence is long and complex, correct identification of sentiment is possible only when all the three steps are used. Often multiple sentiments may be contained in such sentences.

Correlation between in text political ideologies and the moral foundations expressed within that text has been already established. In their work, Johnson and Goldwasser (2018) showed that political ideology and policy frames used by politicians to bias the public towards their stance on an issue are mutually correlated. The authors attempted modelling both the language and framing of issues by politicians on Twitter, to predict the moral foundations used by politicians to justify their stances on issues. Probabilistic graphical modelling showed the usefulness of jointly modelling of abstract political slogans. These were better than unigrams of policy frames for the prediction of the morality underlying political tweets.

In their studies, Karamshuk, Lokot, Pryymak, and Sastry (2016) on the relationship between mainstream and social media in forming public opinion during mass crises, especially the way in which the events are framed in the mainstream news and on social networks, the language used in those frames were aimed at identifying their political slant and partisanship. The authors used dataset consisting of more than $40 \mathrm{M}$ tweets and more than $4 \mathrm{M}$ news articles on the mass protests in Ukraine during 2013-2014 (Euromaidan) and the post-Euromaidan conflict between Russian, pro-Russian and Ukrainian forces in eastern Ukraine and Crimea. The relationship between linguistic markers of a particular political leaning in online media and political slant in news articles and Twitter posts were estimated showing that it is possible to use the method for prediction with high precision.

A machine learning approach for automatic annotation of Spanish and French tweets regarding online reputation of politicians was suggested by Jean-Valere Cossu, Mena, Torres-Moreno, and SanJuan (2014). A simple statistical natural language processing classifier without in-domain training was found suitable for the purpose. The annotation was as good as human annotators and outperformed more specific resources like lexicon or in-domain data. The case of André's Manuel López Obrador, the left candidate to the presidential elections in Mexico in 2012, was used. He had built a strong base of support among people who felt being left behind in the economic growth of Mexico and among the frustrated young generation.

It is well-known that politicians select and use words carefully for their statements aimed at influencing others on an issue. This political strategy is called framing. These frames also indicate the beliefs and positions of the 
politician on the issue. Simple language features like unigrams, bigrams, and trigrams can be used for identifying the general frame of longer congressional speeches as well as short tweets of politicians. Tweets may contain multiple unigrams across different frames and therefore the effectiveness of this approach is limited. Hence, Johnson, Lee, and Goldwasser (2017) proposed a joint model which can use both linguistic features of tweets and ideological phrase indicators. These were extracted using an embedding-based model, which could be used to predict the general frame of political tweets. Some weakly supervised models normally meant for collective classification were used by Johnson, Jin, and Goldwasser (2017) to predict the frames used in political discourse on Twitter. Global probabilistic models showed that by combining features of both lexical features and network-based behavioural features of Twitter, the average unsupervised F1 score was increased by 21.52 points compared to using only lexical baseline.

A model was developed by Shugars and Beauchamp (2019) for argument engagement using a new dataset of Twitter conversations about President Trump. The model included several user, tweet, and thread-level features. The model was used for the prediction of user participation in conversations with over $98 \%$ accuracy. Users tended to argue over wide range of ideological differences. They were also more likely to engage with those who were different from themselves. The emotional content of a tweet had important implications for user engagement. Negative and unpleasant tweets showed tendencies of sustained participation. Even if negative, these extended discussions could narrow down political differences and reduce information bubbles. Thus, a public appetite for engaging in prolonged political discussions which were more than just partisan pot-shots or trolling was noted.

Multimodes, context and linguistic items were shown as parts of the discourse which serve to aid political mobilization, citizen participation and for educational purpose across many social media contexts in the paper by Fakunle (2019) based on the examining the automated multimodes as semiotic nodes and the contextual features used in Abubakar Atiku (the Nigerian political leader) twitter update. Three models were integrated in this research: a revised Herring's multimodal computer mediated communication discourse analytic approach and parts of Kress and Leeuwen's multimodal discourse analysis (Ross \& Rivers, 2018; Nasser \& Kareem, 2018).

A study was undertaken by Stier, Bleier, Lietz and Strohmaier (2018) on whether election candidates addressed the topics most important to the mass audience and to which extent their communication is shaped by the characteristics of Facebook and Twitter in the case of In German federal election campaign 2013. A survey was conducted during the election campaign with open-ended questions. A human-interpretable Bayesian language model was used for identification of political topics. The model was applied to social media messages of candidates and their direct audiences. The candidates and their audience were found to have different priority of topics. Politicians used Facebook and Twitter for different purposes. Twitter was used to a lower extent than Facebook.

\section{Conclusions}

From the findings of the papers, it was evident that politicians use Twitter for both positive and negative purposes. The purpose is determined by which side is the politician. Their patterns observed show that Twitter can be used in a variety of ways for the outcome desired by them. Both linguistic analysis and content analysis of tweets were used by researchers for identifying such trends. Many methods, theories, technologies of manual, machine learning and automatic nature have been used for lexical and linguistic structure of the tweets to derive their true meanings. CDA may be a good tool for capturing the intended meanings from the linguistic properties. None of the methods is perfectly suitable for all types of Twitter analysis. It is recommended that more research on developing standard procedures for various purposes of analysis may be done.

Apart from just the general content, the words used, the structure of the sentence, hidden meanings, use of symbols, some specific methods of presentation have all implications on the political leader as well as the target audience. Textual, lexical and linguistic analyses serve different purposes. However, this does not seem to be well-recognised. The relationship between purpose and methods needs to be clarified by further appropriate research.

Tweets of Trump especially shows the linguistic and content variations he uses for self-promotion, winning supporters for what he believes is good for Americans in the very narrow sense, ridiculing and often insulting opponents, claiming himself to be the sole source and authority of truth and media as the bad boys. Other politicians mainly try to protect themselves against their political opponents for electoral gains or to ward of criticisms, repair image and defend themselves when accused of financial or ethical irregularities. Leading politicians think themselves to be above all and beyond any criticism.

Some attempts to use modelling to predict the future behaviour of politicians in tweeting have been made using 
trends in the past and current trends and different methods of modelling. These models can be used for prediction of future tweets with reasonable precision. But the purpose of such prediction is vague. Past or current tweets may be valid data for predictive models only in so far as the contexts of these tweets continue to exist. If the context changes, tweets may also take different forms of expression. For example, imagine Trump loses his election for the second term. His tweets may be quite different. It is not even possible to guess it, although some possibilities are already looming large (Douglas, 2020) when Trump used his May $26^{\text {th }} 2020$ tweet to insist that mail-in-ballots are not valid due to the possibilities of manipulation he only can see. Mail-in-ballot may be more common in the context of the Corona crisis. It is mainly used by urban dwellers, most of whom are democrats. So, the aim of his tweet is obvious. It is also a refusal to accept defeat. It may be interesting to use modelling approach to probe how tweets of political leaders will change with change of contexts and this is recommended for further work.

There are also possibilities of inadvertent posts with negative implications to be posted. Deletion mechanisms, if done well in time, can reduce the adverse impact of this on the political leader, his party or the target public. Even some tweets of the Pope Francis were prone to such errors. Twitter posts affect both the leader and the people who see, react or retweet them in various ways, but depending on the content and the purpose of the tweet. Only one paper was seen on this topic. Within the limited search done in this paper, it is not possible to say whether more papers exist.

Negative tweets or hate speeches have the potentiality for terrorist and other criminal practices within and outside the country of its origin. At any cost, posts related to negative remarks, intended to spread hatred or provoking murder and violence need to be prevented. However, the absence of an internationally acceptable standard definition for such tweets prevents effective global action on this harmful practice. Culprits can get away by posting such messages from countries where they are not illegal. There is an urgent need for UN and other international organisations, academic experts, civil right activists and Twitter and other social media providers to act on this.

\section{Limitations}

1) Papers available on political tweets are too many. Only five pages of Google Scholar and repeat search of another five pages using a more recent time frame were done. Searching more pages in each case, would presumably yield more papers.

2) Papers beyond 2019 were not included. There are numerous papers published in 2020 alone. Inclusion of at least some of these papers would have given the most modern findings for more useful conclusions.

3) This was an exploratory qualitative review. A qualitative review of this type is highly insufficient for deriving all useful findings from them. A meta-analytical systematic review needs to be undertaken by experts in the field. Moreover, widening the research to include, perhaps compare, other social media contents and websites such as: Facebook, LinkedIn, Snapchat, and etc, is without a doubt imperative.

\section{References}

Aharony, N. (2012). Twitter use by three political leaders: an exploratory analysis. Online Information Review, 36(4), 587-603. https://doi.org/10.1108/14684521211254086

Berman, R., Melumad, S., Humphrey, C., \& Meyer, R. (2019). A tale of two Twitterspheres: political microblogging during and after the 2016 primary and presidential debates. Journal of Marketing Research, 56(6), 895-917. https://doi.org/10.1177/0022243719861923

Carrella, F. (2018). Analysis of The Correlation Between Populist Discourse and Tweet Popularity. Colloquium: New Philologies, 3(2), 27-50. https://doi.org/10.23963/cnp.2018.3.2.2

Casarin, R., Correa, J. C., Camargo, J. E., Dakduk, S., Horst, E. T., \& Molina, G. (2019). What makes a tweet be retweeted? A Bayesian trigram analysis of tweet propagation during the 2015 Colombian political campaign. Journal of Information Science. https://doi.org/10.1177/0165551519886056

Coesemans, R., \& De Cock, B. (2017). Self-reference by politicians on Twitter: Strategies to adapt to 140 characters. Journal of Pragmatics, 116(July), 37-50. https://doi.org/10.1016/j.pragma.2016.12.005

Cohen, R., \& Ruths, D. (2013). Classifying political orientation on Twitter: It's not easy (pp. 91-99). Seventh International AAAI Conference on Weblogs and Social Media. AAAI. Retrieved December 30, 2019, from https://pdfs.semanticscholar.org/80c4/37ee5544da7461f16249373bd8823eb09375.pdf

Colleoni, E., Rozza, A., \& Arvidsson, A. (2014). Echo chamber or public sphere? Predicting political orientation and measuring political homophily in Twitter using big data. Journal of Communication, 64(2), 317-332. 
https://doi.org/10.1111/jcom.12084

Cunha, E., Magno, G., Gonçalves, M. A., Cambraia, C., \& Almeida, V. (2014). He votes or she votes? Female and male discursive strategies in Twitter political hashtags. PloS One, 9(1), e87041. https://doi.org/10.1371/journal.pone.0087041

Dang-Xuan, L., Stieglitz, S., Wladarsch, J., \& Neuberger, C. (2013). An investigation of influentials and the role of sentiment in political communication on Twitter during election periods. Information, Communication \& Society, 16(5), 795-825. https://doi.org/10.1080/1369118X.2013.783608

Douglas, L. (2020, May 29). Will Trump dispute the 2020 election results? His tweets this week suggest so. $\begin{array}{llll}\text { Retrieved June } & 7, & 2020, & \text { from }\end{array}$ https:/www.theguardian.com/commentisfree/2020/may/29/will-trump-dispute-2020-election-results-twitter

Fakunle, R. O. (2019). Heuristic cues and contextual features of selected tweets of Atiku Abubakar: A multimodal perspective. Journal of Language and Linguistics, 6(July), 129-136. Retrieved December 31, 2019, from http://jolledu.com.ng/index.php/joll/article/view/99/81

Genovese, F. (2019). Politics@ Pontifex: International Crises and Political Patterns of Papal Tweets. PS: Political Science \& Politics, 52(1), 7-13. https://doi.org/10.1017/S1049096518001038

Ihebuzor, N., \& Egbunike, N. A. (2018). Fencism: An Unusual Political Alignment in Twitter Nigeria. In Handbook of Research on Civic Engagement and Social Change in Contemporary Society (pp. 364-382). IGI Global. https://doi.org/10.4018/978-1-5225-4197-4.ch021

Jaidka, K., Zhou, A., \& Lelkes, Y. (2019). Brevity is the soul of Twitter: The constraint affordance and political discussion. Journal of Communication, 69(4), 345-372. https://doi.org/10.1093/joc/jqz023

Jaki, S., \& De Smedt, T. (2019). Right-wing German hate speech on Twitter: Analysis and automatic detection. arXiv, 1910, 07518. Retrieved January $2, \quad 2020$ from https://arxiv.org/ftp/arxiv/papers/1910/1910.07518.pdf

Jaworska, S., \& Sogomonian, T. (n.d.). After we\# VoteLeave we can\# TakeControl: political bonding and imagined collectives on Twitter before the Brexit vote. University of Reading. Retrieved January 1, 2020, from https://www.researchgate.net/profile/Sylvia_Jaworska/publication/325719270_After_we_VoteLeave_we_c an_TakeControl_political_bonding_and_imagined_collectives_on_Twitter_before_the_Brexit_vote $/$ links $/ 5$ b1 $\bar{f}$ dc67aca272277fa7fb45/After-we-VoteLeave-we-can-TakeCont

Jean-Valere Cossu, R. A., Mena, A. M., Torres-Moreno, J.-M., \& SanJuan, E. (2014). Bilingual and cross domain politics analysis. Avances en la Ingeniería del Lenguaje y del Conocimiento, 85(December), 9-19. https://doi.org/10.13053/rcs-85-1-1

Johnson, K., \& Goldwasser, D. (2018). Classification of moral foundations in microblog political discourse (Vol. 1: Long Papers, pp. 720-730). Proceedings of the 56th Annual Meeting of the Association for Computational Linguistics, July 2018, Melbourne Australia. Association for Computational Linguistics. https://doi.org/10.18653/v1/P18-1067

Johnson, K., Jin, D., \& Goldwasser, D. (2017). Leveraging behavioral and social information for weakly supervised collective classification of political discourse on Twitter (Vol. 1: Long Papers, pp. 741-752). Proceedings of the 55th Annual Meeting of the Association for Computational Linguistics, July 2017, Vancouver, Canada. Association for Computational Linguistics. https://doi.org/10.18653/v1/P17-1069

Johnson, K., Lee, I.-T., \& Goldwasser, D. (2017). Ideological phrase indicators for classification of political discourse framing on Twitter (pp. 90-99). Proceedings of the Second Workshop on NLP and Computational Social Science, August 2017, Vacouver, Canada. Association for Computational Linguistics. https://doi.org/10.18653/v1/W17-2913

Jones, K. L., Noorbaloochi, S., Jost, J. T., Bonneau, R., Nagler, J., \& Tucker, J. A. (2018). Liberal and conservative values: What we can learn from congressional tweets. Political Psychology, 39(2), $423-443$. https://doi.org/10.1111/pops.12415

Karamshuk, D., Lokot, T., Pryymak, O., \& Sastry, N. (2016). Identifying partisan slant in news articles and Twitter during political crises. In E. Spiro \& Y. Ahn (Eds.), International Conference on Social Informatics (vol. 10046, pp. 257-272). SocInfo 2016. Lecture Notes in Computer Science. Springer, Cham. https://doi.org/10.1007/978-3-319-47880-7_16 
Karkın, N., Yavuz, N., Parlak, İ., \& İkiz, Ö. Ö. (2015). Twitter use by politicians during social uprisings: an analysis of Gezi park protests in Turkey (pp. 20-28). Proceedings of the 16th Annual International Conference on Digital Government Research. ACM. https://doi.org/10.1145/2757401.2757430

Khan, B. F., \& Khan, A. M. (2018). Protecting the Environment from Populism: Policy Implications Drawn from Sentiment Analysis of Trump Supporters' Tweets (p. 22). The Internet, Policy \& Politics Conference 2018. Oxford Internet Institut. Retrieved December 31, 2019, from http://blogs.oii.ox.ac.uk/policy/wp-content/uploads/sites/77/2018/09/IPP2018-Khan.pdf

Li, H., Chen, Y., Ji, H., Muresan, S., \& Zheng, D. (2012). Combining social cognitive theories with linguistic features for multi-genre sentiment analysis (pp. 127-136). Proceedings of the 26th Pacific Asia Conference on Language, Information, and Computation, November 2012, Bali, Indonesia. Faculty of Computer Science, Universitas Indonesia. Retrieved December 30, 2019, from https://pdfs.semanticscholar.org/aecd/5a81ed490d52da645c667c3eb939f63996f8.pdf

Masroor, F., Khan, Q. N., Aib, I., \& Ali, Z. (2019). Polarization and Ideological Weaving in Twitter Discourse of Politicians. Social Media + Society, 5(4), https://doi.org/10.1177/2056305119891220

Meeks, L. (2018). Tweeted, deleted: theoretical, methodological, and ethical considerations for examining politicians' deleted tweets. Information, Communication \& Society, 21(1), 1-13. https://doi.org/10.1080/1369118X.2016.1257041

Nasser, M., \& Kareem, M. (2018). An analytical reconsideration of Donald Trump's tweets. Larq Journal for Philosophy, Linguistics and Social Sciences, 3(28), 44-58. Retrieved January 1, 2020, from https://www.iasj.net/iasj?func=fulltext\&aId=146944

Opeibi, T. (2019). The Twittersphere as Political Engagement Space: A Study of Social Media Usage in Election Campaigns in Nigeria. Digital Studies/Le champ numérique, 9(1), 1-32. https://doi.org/10.16995/dscn.292

Ott, B. L. (2017). The age of Twitter: Donald J. Trump and the politics of debasement. Critical Studies in Media Communication, 34(1), 59-68. https://doi.org/10.1080/15295036.2016.1266686

Pancer, E., \& Poole, M. (2016). The popularity and virality of political social media: hashtags, mentions, and links predict likes and retweets of 2016 US presidential nominees' tweets. Social Influence, 11(4), 259-270. https://doi.org/10.1080/15534510.2016.1265582

Preoţiuc-Pietro, D., Liu, Y., Hopkins, D., \& Ungar, L. (2017). Beyond binary labels: political ideology prediction of twitter users (Vol. 1: Long Papers, pp. 729-740). Proceedings of the 55th Annual Meeting of the Association for Computational Linguistics, Vancouver, Canada. ACL. https://doi.org/10.18653/v1/P17-1068

Ramanathan, R., Bee, H. T., \& Paramasivam, S. (2017). Lexis in Political Ideas on Twitter. International Journal of Applied Linguistics and English Literature, 6(7), 342-352. https://doi.org/10.7575/aiac.ijalel.v.6n.7p.342

Ross, A. S., \& Rivers, D. J. (2018). Discursive deflection: Accusation of "fake news" and the spread of mis-and disinformation in the Tweets of President Trump. Social Media + Society, 4(2). https://doi.org/10.1177/2056305118776010

Shapiro, M. A., Hemphill, L., \& Otterbacher, J. (2018). Updates to Congressional Speech Acts on Twitter. University of Michigan. Retrieved January 1, 2020, from https://deepblue.lib.umich.edu/bitstream/handle/2027.42/145592/Updates\%20to\%20Congressional\%20Spe ech\%20Acts\%20on\%20Twitter\%20-\%20APSA\%202018.pdf?sequence=1\&isAllowed=y

Shugars, S., \& Beauchamp, N. (2019). Why Keep Arguing? Predicting Engagement in Political Conversations Online. SAGE Open, 9(1), https://doi.org/10.1177/2158244019828850

Stieglitz, S., \& Dang-Xuan, L. (2012). Political communication and influence through microblogging-An empirical analysis of sentiment in Twitter messages and retweet behavior (pp. 3500-3509). 45th Hawaii International Conference on System Sciences, 4-7 Jan. 2012, Maui, HI, USA. IEEE. https://doi.org/10.1109/HICSS.2012.476

Stier, S., Bleier, A., Lietz, H., \& Strohmaier, M. (2018). Election campaigning on social media: Politicians, audiences, and the mediation of political communication on Facebook and Twitter. Political Communication, 35(1), 50-74. https://doi.org/10.1080/10584609.2017.1334728

Tatman, R., Stewart, L., Paullada, A., \& Spiro, E. (2017). Non-lexical features encode political affiliation on 
twitter (pp. 63-67). Proceedings of the Second Workshop on NLP and Computational Social Science, August 17, Vancouver, Canada. Association for Computational Linguistics. https://doi.org/10.18653/v1/W17-2909

Teixeira, C. R., Kurtz, G., Leuck, L. P., Tietzmann, R., de Souza, D. R., Lerina, J. M., ... Silveira, M. S. (2018). Humor, support and criticism: a taxonomy for discourse analysis about political crisis on Twitter (p. 68). Proceedings of the 19th Annual International Conference on Digital Government Research: Governance in the Data Age, dg.o'18, May 30-June 1, 2018, Delft, Netherlands. ACM. https://doi.org/10.1145/3209281.3209330

Torregrosa, J., Thorburn, J., Lara-Cabrera, R., Camacho, D., \& Trujillo, H. M. (2019). Linguistic analysis of pro-ISIS users on Twitter. Behavioral Sciences of Terrorism and Political Aggression, 1-15. https://doi.org/10.1080/19434472.2019.1651751

Volkova, S., \& Jang, J. Y. (2018). Misleading or falsification: Inferring deceptive strategies and types in online news and social media (pp. 575-583). Companion Proceedings of the The Web Conference 2018, International World Wide Web Conferences Steering Committee, April 23-27, 2018, Lyon, France. ACM. https://doi.org/10.1145/3184558.3188728

Wodak, R., \& Meyer, M. (2009). Critical Discourse Analysis: History, Agenda, Theory, and Methodology. In R. Wodak \& M. Meyer (Eds.), Methods for critical discourse analysis (2nd ed., pp. 1-33). Sage. Retrieved December 27, 2018,

https:/us.corwin.com/sites/default/files/upm-binaries/24615_01_Wodak_Ch_01.pdf

\section{Copyrights}

Copyright for this article is retained by the author, with first publication rights granted to the journal.

This is an open-access article distributed under the terms and conditions of the Creative Commons Attribution license (http://creativecommons.org/licenses/by/4.0/). 